\title{
Ellagitannins - Compounds From Pomegranate as Possible Effector in Steroidogenesis of Rabbit Ovaries
}

\author{
D. PACKOVA ${ }^{1}$, A. A. CARBONELL-BARRACHINA ${ }^{2}$, A. KOLESAROVA ${ }^{1}$ \\ ${ }^{1}$ Department of Animal Physiology, Faculty of Biotechnology and Food Sciences, Slovak \\ University of Agriculture in Nitra, Slovak Republic, ${ }^{2}$ Department of Agrifood Technology, \\ University of Miguel Hernández, Orihuela (Alicante), Spain
}

Received November 25, 2014

Accepted April 3, 2015

\begin{abstract}
Summary
This study has observed possible effect of ellagitannins compounds from pomegranate on process of steroidogenesis in ovaries. The aim of the study was to investigate the possible effect of punicalagin on secretion of steroid hormones progesterone, androstenedione, testosterone and $17 \beta$-estradiol by ovarian fragments of rabbits in vitro. Ovarian fragments from sexually mature female New Zealand white rabbits $(n=20)$ were incubated without (control group) or with punicalagin at various doses 1,10 and $100 \mu \mathrm{g} \cdot \mathrm{ml}^{-1}$ for $24 \mathrm{~h}$. Hormones were evaluated by ELISA (The Enzyme-Linked Immunosorbent Assay). Data showed that progesterone and 17ß-estradiol (but not androstenedione and testosterone) release by rabbit ovarian fragments was significantly affected by punicalagin addition at various doses. Punicalagin (at $100 \mu \mathrm{g} \cdot \mathrm{ml}^{-1}$ ) significantly $(P<0.05)$ increased progesterone secretion. On the other hand, the release of $17 \beta$-estradiol was significantly $(P<0.005)$ decreased by punicalagin addition (at $10 \mu \mathrm{g} \cdot \mathrm{ml}^{-1}$ ). Our results suggest that punicalagin could have dose-dependent impact on secretion of steroid hormones progesterone and $17 \beta$-estradiol by rabbit ovarian fragments and it may be effector in process of ovarian steroidogenesis.
\end{abstract}

\section{Key words}

Ellagitannins - $17 \beta$-estradiol - Punicalagin - Pomegranate • Steroidogenesis

\section{Corresponding author}

A. Kolesarova, Department of Animal Physiology, Faculty of Biotechnology and Food Sciences, Slovak University of Agriculture, 94976 Nitra, Slovak Republic.

E-mail: Adriana.Kolesarova@uniag.sk
Ellagitannins (ETs) are bioactive polyphenols abundant in some fruits (Landete 2011). ETs are included within the so-called hydrolysable tannins that can be hydrolyzed producing ellagic acid via spontaneous lactonization of hexahydroxydiphenic acid (Larrosa et al. 2006). Ellagic acid is a part of polyphenol - punicalagin, which is included and responsible for antioxidant activity in pomegranate. Pomegranate is a well-known source of many valuable substances, except for hydrolysable tannins (punicalagins and punicalins) (Gil et al. 2000), contains condensed tannins (proancyanidins) (Poyrazoglu et al. 2002), anthocyanins (Hernández et al. 1999), phenolic acids (ellagic acid, gallic acid) (Mousavinejad et al. 2009). Papoutsi et al. (2005) investigated the influence of ellagic acid on the activity of the estrogen receptor subtypes $\alpha$ and $\beta$ in HeLa cells. The aim of our study was to examine the secretion of steroid hormones progesterone, androstenedione, testosterone and $17 \beta$-estradiol by rabbit ovarian fragments after punicalagin addition as main ellagitannin of pomegranate. Sexually mature female New Zealand white rabbits $(n=20)$ from an experimental farm of the Animal Production Research Centre Nitra, Slovak Republic were used. Rabbits (age 150 days, weight $4.00 \pm 0.5 \mathrm{~kg}$ ) were housed in individual flat-deck wire cages under a constant photoperiod of $12 \mathrm{~h}$ of day-light, the temperature $20-24{ }^{\circ} \mathrm{C}$ and humidity $55 \pm 10 \%$. Institutional and national guidelines for the care and use of animals were followed, and all experimental procedures were approved by the State Veterinary and Food Institute of Slovak Republic (no. 3398/11-221/3) and Ethics committee. 


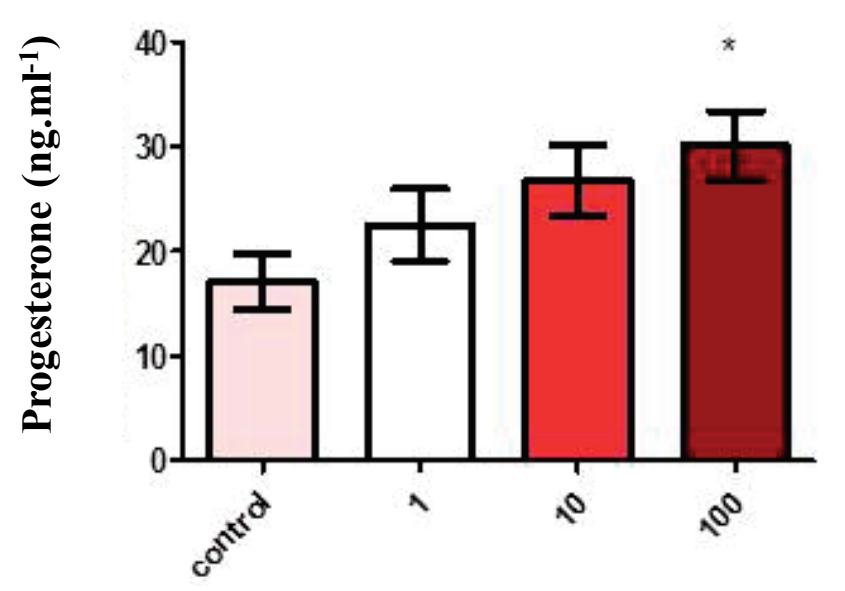

Punicalagin ( $\mu \mathrm{g} \cdot \mathrm{ml}^{-1}$ )

Fig. 1. Dose-dependent effect of punicalagin on progesterone (ng. $\mathrm{ml}^{-1}$ ) secretion by rabbit ovarian fragments. Significant $(P<0.05)$ differences between control and experimental groups. The results were evaluated by One Way ANOVA. ELISA.

Ovaries were collected and transported to the laboratory at the ambient temperature in a glass container within 30 min of slaughter. Thereafter ovaries were washed in sterile physiological solution and dissected using a blade knife to 8 approximately equal parts (weight 4.8-5.6 mg). These ovarian fragments were washed again two times in sterile physiological solution and cultured in $1 \mathrm{ml}$ of medium supplemented with $10 \%$ fetal bovine serum and $1 \%$ antibiotic-antimycotic solution and without (control group) or with punicalagin (SigmaAldrich, St. Louis, MO, USA) addition at various concentrations - 1, 10, $100 \mu \mathrm{g} \cdot \mathrm{ml}^{-1}$ for $24 \mathrm{~h}$. Progesterone, androstenedione, testosterone and $17 \beta$-estradiol concentrations in culture medium were evaluated by ELISA (The Enzyme-Linked Immunosorbent Assay, Dialab, Wiener Neudorf, Austria). The absorbance was determined at a wave length $450 \mathrm{~nm}$ on the microplate ELISA reader (Thermo Scientific Multiskan FC, Vantaa, Finland). Each experimental group was represented by four culture wells of ovarian fragments (each dose $=4$ replicates, biological parallels). Assays of hormone levels in the culture media were performed in duplicate. The data are presented as means of values obtained from three separate experiments performed on separate days using separate pools of ovaries from 20 animals. Significance of differences between the control and experimental groups were evaluated by one-way ANOVA using the statistical software GraphPad Prism 5 Demo (GraphPad Software Incorporated, San Diego, California, USA). The data are expressed as means \pm SEM. Differences were compared for statistical significance at $P<0.05$.

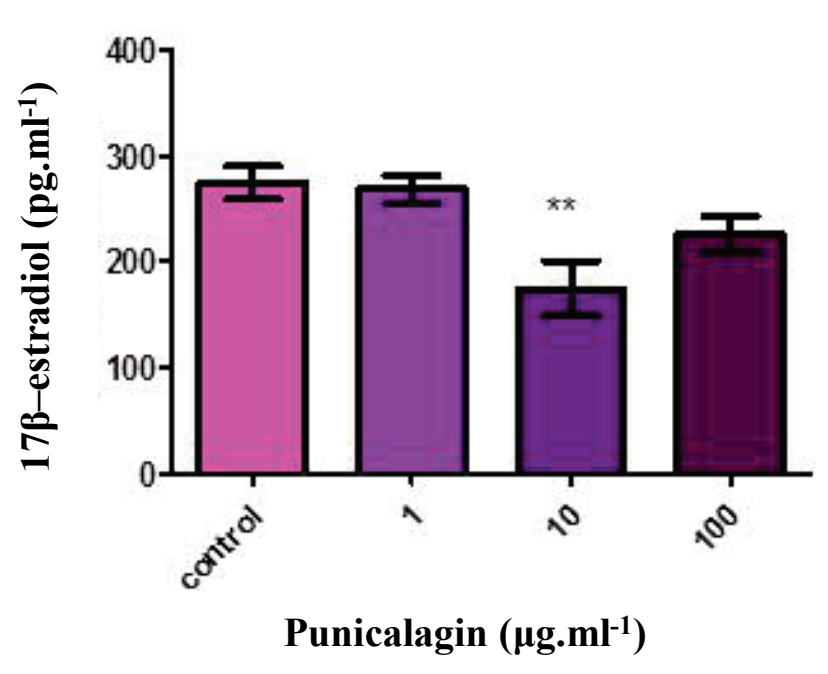

Fig. 2. Dose-dependent effect of punicalagin on $17 \beta$-estradiol (pg. $\mathrm{ml}^{-1}$ ) secretion by rabbit ovarian fragments. Significant $(P<0.005)$ differences between control and experimental groups. The results were evaluated by One Way ANOVA. ELISA.

Punicalagin influenced the secretion of steroid hormones progesterone and $17 \beta$-estradiol by rabbit ovarian fragments (Figs 1,2). Firstly, punicalagin at concentration $\quad 100 \mu \mathrm{g} . \mathrm{ml}^{-1} \quad$ significantly $\quad(P<0.05)$ increased the release of progesterone (Fig. 1). Secondly, values of androstenedione were very low and the concentration in each case was under measurable limits. Thirdly, similarly testosterone levels were low. Fourthly, punicalagin at concentration $10 \mu \mathrm{g} \cdot \mathrm{ml}^{-1}$ significantly $(P<0.005)$ decreased the release of $17 \beta$-estradiol.

Influence of punicalagin on the release of progesterone could indicate that the backdoor pathway of steroid biosynthesis might be under the impression of punicalagin. Recently, Ming et al. (2014) used pomegranate extraction the prostate cancer cells to suggest that steroid biosynthesis might favour the backdoor pathway over the classical $\Delta 4$ and $\Delta 5$ pathways. They described the effect of pomegranate extract on androgen biosynthesis pathways specifically using two prostate cancer cell lines and prostate cancer mouse model. Ming et al. (2014) described androstenedione in downtrend. In our study levels of androstenedione were very low and in most of the samples were under the measurable spectrum. Ming et al. (2014) also presented most of the steroids (testosterone and dihydrotestosterone) in very low concentrations in prostate cancer cells and culture media, while dehydroepiandrosterone and progesterone were used as precursor substrates to help boost cell production of steroids, but testosterone was significantly decreased in samples treated with pomegranate extracts. In our study 
the levels of testosterone in culture medium were low. Punicalagin, as main ellagitannin of pomegranate, had influence on secretion of $17 \beta$-estradiol as final product of the pathway. At the concentration $10 \mu \mathrm{g} \cdot \mathrm{ml}^{-1}$ significant $(P<0.005)$ decrease was noted in rabbit ovarian fragments. Using lyophilized fresh pomegranate juice, Kim et al. (2002) reported that phenols from pomegranate inhibit $55 \%$ estrogen activity by normal human breast epithelial cells. Punicalagin, which was used in the present study or its derivatives (ellagic acid etc.) might have a possible effect on certain steps in process of steroidogenesis. Similarly, the effect of other antioxidant from red grape - resveratrol, as possible effector in the process of steroidogenesis, was shown in previous study (Kolesarova et al. 2012).

Our results suggest that punicalagin could have dose-dependent impact on secretion of steroid hormones progesterone and $17 \beta$-estradiol by rabbit ovarian fragments and it may be effector in process of ovarian steroidogenesis.

\section{Conflict of Interest}

There is no conflict of interest.

\section{Acknowledgements}

This work was supported by the Ministry of Education, Science, Research and Sports of the Slovak Republic no. 1/0022/13, Slovak Research and Development Agency of the Slovak Republic no. APVV-0304-12, RGB Net (COST Action TD1101), European Community under project no. 26220220180: Building Research Centre „AgroBioTech".

\section{References}

GIL MI, TOMÁS-BARBERÁN FA, HESS-PIERCE B, HOLCROFT DM, KADER AA: Antioxidant activity of pomegranate juice and its relationship with phenolic composition and processing. J Agric Food Chem 48: 4581-4589, 2000.

HERNÁNDEZ F, MELGAREJO P, TOMÁS-BARBERÁN FA, ARTÉS F: Evolution of juice anthocyanins during ripening of new selected pomegranate (Punica granatum) clones. Eur Food Res Technol 210: 39-42, 1999.

KIM ND, MEHTA R., YU W, NEEMAN I, LIVNEY T, AMICHAY A, POIRIER D, NICHOLLS P, KIRBY A, JIANG W, MANSEL R, RAMACHANDRAN C, RABI T, KAPLAN B, LANSKY E: Chemopreventive and adjuvant therapeutic potential of pomegranate (Punica granatum) for human breast cancer. Breast Cancer Res Treat 71: 203-217, 2002.

KOLESAROVA A, CAPCAROVA M, MARUNIAKOVA N, LUKAC N, CIERESZKO RE, SIROTKIN AV: Resveratrol inhibits reproductive toxicity induced by deoxynivalenol. J Environ Sci Health A Tox Hazard Subst Environ Eng 47: 1329-1334, 2012.

LANDETE JM: Ellagitannins, ellagic acid and their derived metabolites: a review about source, metabolism, function and health. Food Res Int 44: 1150-1160, 2011.

LARROSA M, TOMÁS-BARBERÁN FA, ESPÍN JC: The dietary hydrolysable tannin punicalagin releases ellagic acid that induces apoptosis in human colon adenocarcinoma Caco-2 cells by using the mitochondrial pathway. J Nutr Biochem 17: 611-625, 2006.

MING DS, PHAM S, DEB S, CHIN MY, KHARMATE G, ADOMAT H, BEHESHTI EH, LOCKE J, GUNS ET: Pomegranate extracts impact the androgen biosynthesis pathways in prostate cancer models in vitro and in vivo. J Steroid Biochem Mol Biol 143: 19-28, 2014.

MOUSAVINEJAD G, EMAM-DJOMEH Z, REZAEI K, KHODAPARAST MHH: Identification and quantification of phenolic compounds and their effect on antioxidant activity in pomegranate juices of eight Iranian cultivars. Food Chem 115: 1274-1278, 2009.

PAPOUTSI Z, KASSI E, TSIAPARA A, FOKIALAKIS N, CHROUSOS GP, MOUTSATSOU P: Evaluation of estrogenic/antiestrogenic activity of ellagic acid via the estrogen receptor subtypes ER $\alpha$ and ER $\beta$. J Agric Food Chem 53: 7715-7720, 2005.

POYRAZOGLU E, GOKMEN V, ARTIK N: Organic acids and phenolic compounds in pomegranates (Punica granatum L.) grown in Turkey. J Food Compost Anal 15: 567-575, 2002. 